УДК 821.161.1.09

ББК 83

\section{C.A. Хомяков}

\section{«СОКРАЩАЯ}

РАССТАВАНИЕ"

ВЕНИАМИНА БОРИСОВА: МЕТАМОРФОЗЫ

ВРЕМЕНИ

И ПРОСТРАНСТВА

Поэтический сборник В. Борисова «Сокращая расставание» (2018) анализируется с точки зрения пространственно-временной организации и семантики рамочных элементов. Архитектоника книги базируется на противопоставлении пространственных и временных форм. Такое построение непосредственно связано с семантикой стихов Борисова, лирический герой которых проходит путь преодоления одиночества и уныния. Художественное пространство и время формируется также на уровне многочисленных аллюзий и отсылок.

Ключевые слова: время, пространство, «Сокращая расставание», Вениамин Борисов, хронотоп, рамочные элементы.

DOI 10.18522/1995-0640-2020-4-158-168

Хомяков Сергей Александрович - канд филол. наук; старший преподаватель подготовительного отделения Московского медико-стоматологического университета им. А.И.Евдокимова

Тел.: 8-926-394-94-01

E-mail: khomjakov.sergey@mail.ru

(C) Хомяков С.А., 2020 г.

\section{Введение}

Новый век - XXI век, точнее его самое начало - ознаменовался иным подходом к поэтическим текстам: во-первых, не только книга стихов, но и социальные сети позволили поэтам «расширить» привычное представление о сборнике; во-вторых, стало проще издать книгу, в-третьих, молодые авторы, в отличие от поэтов советского прошлого, стремятся в одной книге совместить несколько видов искусств. Цель исследования заключается в том, чтобы проанализировать книгу стихов «Сокращая расставание» В. Борисова как один из видов поэтических сборников XXI в., определить некоторые закономерности. Кроме того, интересным представляется то, как в сборнике, в котором воспроизводятся современные реалии, поэту удается оперировать временем и пространством. Эти категории нам видятся базовыми в структуре любого поэтического сборника. До сих пор нет ни одного исследования, посвященного поэтике В. Борисова, а также прошедшее двадцатилетие нуждается в анализе и описании - в этом заключается актуальность исследования, что обусловило выбор методов анализа - текстологического и герменевтического. При литературоведческом анализе художественного произведения - если это касается поэтического сборника - каждый элемент [Верина, 2016] оказывается значимым, потому что, выполняя определенную роль, он отвечает авторской задаче - расширить художественное пространство и объединить входящие в состав сборника стихотворе- 
ния. В последнее десятилетие наметилась четкая тенденция [Голубков, 2018], в основе которой - рассмотрение книги стихов как новой жанровой формы [Лекманов, 2010]. В то же время анализ рамочно-заголовочного комплекса произведения является прогрессивным направлением [Хомяков, 2018, с. 61].

\section{Исследование и его результаты}

Каждый поэт вступает в сложные отношения со временем и с пространством. Молодой поэт и драматург Вениамин Борисов, в 2018 г. выпустивший свой третий сборник стихов под названием «Сокращая расставание», называет его в предисловии «средством, которое способно помочь сократить расставание или < ...> сократить боль» [Борисов, 2018, c. 85; далее цитаты приводятся по этому изданию с указанием страниц в круглых скобках]. Борисов прямо объясняет смысл названия своего сборника, когда говорит, что во время написания составивших книгу стихов автору довелось «узнать, что такое счастье и что такое - его антоним» (с. 86). Принцип противопоставления, полярности - ключевой во всем сборнике.

В книге Борисова 68 стихотворений, каждое из которых озаглавлено (единственное исключение - «То многое, что я не выразил...»). Практически все заголовки непосредственно связаны с лирическим сюжетом. Борисов отказывается от указания дат в конце каждого стихотворения, создавая ощущение целостности книги, где каждая страница - продолжение предыдущей, и разрушая связь с реальным временем. 12 стихотворений открываются эпиграфами из самых разных произведений от рок-групп «Сплин» и «Гражданская оборона» до Набокова и Евтушенко [Клинг, Орлова, 2019]. Несмотря на разнообразие цитируемых текстов, все стихотворения с эпиграфами объединены семантически: в них всегда речь идет о разрыве и расставании. На отсутствие единой и простой композиционной мотивировки указывают и эпиграфы ко всему сборнику, взятые из популярного советского фильма «Бриллиантовая рука» (1969), детективного романа Джона Фаулза «Коллекционер» (1963) и «Евгения Онегина» А. С. Пушкина [Каминская, 2019]. Таким образом, все элементы - название, вступление, эпиграфы, стихотворения, цветные рисунки (!) - трактуются как части единой системы и связаны с мотивами разрыва и преодоления.

Названия произведений представляют собой факт или указание на событие, а строка, вынесенная в название, всегда используется в конкретном стихотворении, усиливая таким образом повествовательную сторону и композиционную целостность произведения [Холиков, 2019]. Например, первое стихотворение - «Сокращая расставание» - рассказывает о том, что предпринял, «отнеся стихи в издательство», герой, чтобы «освободиться от оков»: «Я сохраню в них прах страдания, / я будущее спрячу в них, / тем самым наше расставание / хоть ненамного сократив» (с. 83). Ни капли не иронизируя, как во вступлении к сборнику, Борисов не претендует на славу и «не воздвигает памятник», а «прячет 
грусть», не вступает в полемику с поэтом «золотого века» и прячет стихи «в тиши прилавков». Однако автор ищет своего читателя, чтобы «в диалоге с кем-нибудь» понять «свою лучше суть» (с. 83).

Давая каждому стихотворению название (это всегда не первая строка произведения), Борисов не только «сокращает» расстояние между лирическим героем и читателем, но и формирует определенную аудиторию, помещая в сборник цветные иллюстрации. Соединяя два вида искусства - временно́е и пространственное - и расширяя границы текста, Борисов подчиняет картинки некой иерархии: сцена в метро (с. 71) - расставание (отдаление, разрыв отношений); фонтан (символ быстротечности времени) в ночном парке (с. 59) - пустота, тишина, одиночество; силуэт мужчины на фоне многоквартирного дома (с. 38) дистанция, два пространства, что отсылает к первой иллюстрации; силуэт молодого человека на фоне открывающегося вида из окна (с. 28) одиночество, ожидание и надежда; девушка в легком платье, держащая ветку в руке (с. 18), - символ надежды; силуэты молодой пары в машине (c. 8) - практически «сокращенное» расстояние; силуэты молодого человека и девушки, которые держатся за руки (с. 2) - «преодоление» расставания. Благодаря визуальному ряду, который также построен вокруг названия сборника, история лирического героя рассказывается еще раз.

Изображение разных форм - ближнего и дальнего, закрытого и открытого - пространства, как в текстах, так и на иллюстрациях, усиливает эстетический эффект от всей книги. Время года, изображенное на рисунках, - лето, семантика и образы которого появляются на протяжении всего сборника. Автор, ограничивая события определенным топосом - Москвой - и обращаясь к различным видам пространств, изображает в большинстве своем открытые и незамкнутые пространства, преодолеть которые постепенно удается лирическому герою. В стихах Борисова описательность и повествовательность преобладают над динамикой, и это роднит сборник с живописью, где изображаются статичные картины. Физическое или циклическое время или заявлено конкретно («сегодня»), или присутствует в аллегорических образах с сопутствующими мотивами. Эффекта «замедленного» времени удается достичь не только отсутствием указания на даты, но и привязанностью к общепринятым или национальным событиям.

Названия стихотворений - это эпизоды, вырванные из памяти лирического героя. Первое стихотворение «Сокращая расставание» - точка, с которой смотрит в прошлое лирический герой, чем и обусловливается композиция сборника (обратный хронологический порядок) и названия последующих произведений. «Дерево» рассказывает о разрыве отношений и потере внутренней гармонии главным героем, однако минорные ноты его настроения сменяются более оптимистичными в стихотворении «Под облаками»: «Я назначаю встречу здесь, / когда-нибудь, под облаками» (с. 77). Стихотворения соотносятся на уровне образов и мотивов не только со следующими прямо за ними произведениями, но и с другими, расположенными в разных частях сборника. Например, 
«Бутылка полусладкого» корреспондирует с третьей иллюстрацией и повествует о невыносимости бытия. Художественное пространство этого стихотворения усложняется довольно хитроумной аллюзией: строка «В какой-то дымке матовой» отсылает к популярной песне группы «Земляне», а следом за ней идет строка, апеллирующая к творчеству А. А. Ахматовой.

В стихотворении «Попытка эмиграции», предстающим небольшой новеллой о состоянии лирического героя, который не может найти своего места, стержнем становятся рассуждения о несостоявшемся счастье: «А если б я пожил здесь годик, / <... / и вскоре стало бы мне скучно / от предсказуемости всей» (с. 79). Одиночество лирического героя сопоставляется с пустынным городом, в котором детали («аллеи», «здания» и т. д.) предстают обособленными и не создают цельного образа. Использование различных видов параллелизма - прямого или отрицательного - и смешение разговорного и литературного стиля создают эффект романтического двуемирия: «Есть у меня родимый город, / в дождях, в раскопках и в дыму, / но он такой один, бесспорно, / и мне пора лететь к нему» (с. 78).

Мотив одиночества - один из главных в сборнике - усиливается от стихотворения к стихотворению, что связано с ощущением безвыходности и безысходности. Не случаен и эпиграф, из песни рок-группы «Сплин» «Выхода нет», усиливающий указанную семантику в стихотворении «Знобит»: «Когда тяжёл короткий путь из арки / и с телом невозможен компромисс, / когда вдруг открывают алкомаркет / на месте, где всегда был «Букинист», / когда друзей ты не встречаешь больше: / кто жизнью бит, кто просто далеко, / когда и ты потерянный такой же, / как все они, - становится легко» (с. 76). Интересным представляется использование противоречащих и даже исключающих друг друга слов - «алкомаркет» и «Букинист», потому что городское пространство вторит внутреннему состоянию лирического героя. Автору удается даже передать сущностные основы элегического жанра - философское и психологическое размышление, растворение сознания (действительности) в этих рассуждениях и мечте: «Когда свободу с мясом вырывают, / оставив мелкий шрам, судьбы зигзаг, / только тогда ты точно понимаешь, / что жил, живёшь и будешь жить вот так» (с. 86).

Лирический герой, озадаченный причинами разрыва отношений, «собирая по памяти портрет», воспоминает событие - предстоящий новый год - и иронично винит во всем «нож, упавший со стола». Однако, как бы лирический герой ни пытался сократить «расставание» и превратить «май» в «недоянварь» (т. е. в декабрь), ему это не удается. Данная тема находит продолжение в стихотворении «По марту», где, несмотря на то что «судъба - не Центризбирком» (с. 75), все равно утверждается рутинность и неизменность происходящих событий в жизни «недочеловека» благодаря отсылке к творчеству М. А. Булгакова, которая, как и в случае с Ахматовой и группой «Земляне», зиждется на связанной с ней аллюзией на факт популярной культуры: «Народ роняет бутерброд / 
вниз маслом, Аннушкой разлитым» (с. 61). Эффект разделенного пространства и времени усиливается темпоральной и цветовой семантикой [Тахо-Годи, 2019], что, несмотря на повествовательную составляющую этого стихотворения, свидетельствует о беспомощности героя как перед капризами природы, так и перед ударами судьбы, выразившихся в «курантах соло».

Логичным становится продолжение истории неразделенной любви в стихотворении «То многое, что я не выразил...», где, развивая новогоднюю тему («изморозъ», «полночь» (с. 74)), лирический герой болезненно воспринимает каждую новую встречу с возлюбленной, уверяя себя, что они «тепло и горько попрощаются». Именно в этом стихотворении достигает своего апогея тема творчества, недосказанности и отношения поэта к вечности, которая вершит человеческие судьбы и которой лирический герой ничего не может противопоставить («Всё будет так, как нужно вечности»). В связи с этим указание на точный год и месяц («Оно останется на совести / семнадиатого года, месяиа - четвертого...») выглядит песчинкой «в невесомости» (с. 74), а время предстает цикличным, потому что события прошлого, смешиваясь, могут повториться, однако их исход будет трагическим. Последние шесть строк отсылают к стихотворению А. А. Блока «Ночь, улица, фонарь, аптека...», которое обыгрывается в «„Арсенал“ - „Кристал Пэлас“», однако, несмотря на схожую синтаксическую структуру (парцелляциия, назывные предложения и т. д.), рифма меняется на «встарь - вратарь».

Продолжая идею всевластной судьбы, Борисов в следующем стихотворении - «Обыкновенная история» - рассказывает о том, что «судъбу ей кто-то подменил» и долгожданное счастье, родившееся «на лавочке», «жизнъ» (с. 73) им не подарила. Переход от конкретной влюбленной пары к образам толпы и нищих, среди которых они «исчезли», лишь усиливает лейтмотив одиночества всего сборника Борисова. Иллюстрация, помещенная после данного стихотворения, с идеей разных непересекающихся - жизненных путей, вместе с выбранным местом метро, где всегда много людей, спешащих куда-то и зачем-то, завершает драматическое воспоминание, выхваченное из памяти.

Значимым оказывается стихотворение «Море», в котором лирический герой, «последний месяи» (с. 66) проведя без возлюбленной, жил лишь для того, чтобы она его «не позабыла». Лирический герой, боясь потерять возлюбленную, готов стать ее ангелом-хранителем и «пополам сломать стрелки», чтобы она не «стала с толпою заодно». Море в стихотворении символизирует не только бездну чувств лирического героя: Борисов переосмысляет традиционный романтический образ, и «сны о море» видит возлюбленная, а не лирический герой, который только «строит» для нее «причал». «Утро на щыпочках проникнет в дом», разбудив и лишив ее сна, а влюбленному «Арлекину» остается «ждать, когда же будет на этом свете вновь темно (с. 65), чтобы встретиться с ней. Обращение лирического героя к возлюбленной в последних строках - это крик человека, доведенного до отчаяния из-за неспособности что-либо 
изменить. Это признание ( Послушай, заключим пари, / что ты сегодня до зари / не вспомнишь, что тебе приснилось, / ведь море у тебя внутри» (c. 64)) оказывается знакомо и близко практически каждому человеку, оказывавшемуся на месте героя. Образ «девчонки», которая «разбила всю жизнь» поэтам, ставшими одинокими и слившимися с безликой толпой, возникает в стихотворении «Сходили с ума поэты», проникнутом мотивами сумасшествия и семантикой психиатрической больницы: «Свет им гасили рано / в белом чужие люди» (с. 64). Нужно не забывать, что лирический герой - поэт, о чем сказано уже в первом стихотворении «Сокращая расставание».

Урбанистическая тема занимает немаловажное место во всем сборнике, как на уровне художественных деталей, характеризующих столицу («Очки, оттенка марганщовки, / «Chopard», «Moschino», «Louboutin» / и кофе с запахом лаванды...»), которая предстает, несмотря на устоявшееся словосочетание «дорогие москвичи» (не обращение!), бездушной и бездумной в одноименном стихотворении. Подмена духовных ценностей превратила москвичей в «игрушки из цветной коробки», а использованная в начале стихотворения синекдоха («москвич, одетый кто во что») сменяется авторским сочувствием: «И дорогие москвичи / ложатся спать в дешёвом мире». Эта тема находит продолжение в стихотворении «Как дети», потому что «быть скромным стало вдруг немодно» - это качество - застенчивость, скромность - приводит лирического героя к потере любимого человека в мире, где добивается всего тот, кто привык «нагло брать свое».

Столица в сборнике предстает местом, где разворачиваются основные события, хотя «плотность» пространства определена небольшим количеством людей (толпой) - лирическому герою приходится «nродираться через трафик, рекламу, трейлеры кино» (с. 63), но достичь цели не удается. Он «застревает где-то между комментов, поздравлений, дат» (с. 63). Город, подобно Петербургу Достоевского, обезличивает человека, который становится не участником событий, а их свидетелем: «Так сам тьь в эту ленту канешь, / хлебнув чужих проблем сполна, / а вот она выходит замуж, / а вот - ребёнок. Всё. Хана» (с. 63). При этом анафоры создают эффект сменяющихся кинокадров или размещенных в социальной сети фотографий, о которых говорилось ранее. «Насыщенность» пространства достигается и на уровне мотива одиночества и «тесноты», и на уровне отсутствия каких-либо ярких красок - воспоминания со временем стираются. «Интернет» уже прямо, а не метафорически представлен паутиной, «сетью», которая уничтожает время, бесконечно ускользающее от лирического героя. «Спасти» время можно, если «не платить за Интернет» (с. 62). Пространство, воспринимаемое без связи со временем, предстает статичным и обуславливает соответствующую «точку зрения» лирического героя. Наличие разговорной лексики, варваризмов - это не только то, что не позволяет «сократить расставание» и сказать о самом главном, но и элементы, характеризующие город в определенный временной промежуток. В стихотворении 
«По марту» применен как раз кинематографический принцип, и образ Судьбы, о которой сказано в начале стихотворения, представлен в виде смены времен года.

Воспоминания, лежащие в основе стихотворения «Больше 100 км от города», позволяют лирическому герою говорить и о «футбольных воротах из двух кольшков», и «взрослом разговоре под пиво с корюшкой», и о «бродячих собаках, кличках глупьх», и о «том самом доме из дерева» (с. 60). Таким образом, столичное пространство противопоставляется деревенскому - живому, «искреннему», позитивному. При этом в названии не содержится указания на злополучные «100 км от города», о которых помнит старшее поколение. Сцена вынужденного отъезда («машины... из детства по щебёнке увозили нас») становится чертой, отделяющей беззаботную пору и время «сложного выбора» и наслаждений («теперь нам подавай юга, экзотику»). Антитеза «теперь - детство» усиливается мотивом расставания, когда «забыли навестить товарища» (отсылка к образу Фирса из «Вишневого сада» А. П. Чехова). Противопоставленность разных временных периодов наблюдается и в других стихотворениях: например, в «Помнишь?» - события конца 1990-х и начала 2000-х гг. Заканчивая стихотворение, Борисов отмечает, что «просто жил, вставая в семь, не думая, что станешь взросльм» (с. 60). Оказывается, что все происходившие в детстве события - пусть их было немного - были преисполнены смысла и радости, в отличие от событий сегодняшнего дня.

Стихотворение «Фонтаны», связанное с предыдущими («Пруды») на семантическом и мотивном уровне, становится финалом любовной трагедии, когда, несмотря на то, что «по лезвию одной судьбы мы шли к машине», лирический герой утрачивает недавно обретенную мечту. Не случайным предстает закрытое и замкнутое пространство леса, противопоставленного урбанистическому пространству и встающего в ряд с образами из детства. Фонтан, как и, например, «снег в мае» (с. 75), - это пространственно-временные детали, разбросанные по сборнику, но именно они организуют пространственно-временную систему художественного мира Борисова. Поэтому предстает логичной цветная иллюстрация вечернего пейзажа с фонтаном и бегущей водой (символ быстротечности времени) на фоне леса, оберегающего мечту, а следующее стихотворение называется по-детски - «Ириски» и наполнено уверенностью в том, что лирический герой будет счастлив.

Воспоминание - способ преодоления расстояния, или «расставания» («Банкет и опустевший зал / в моей остались памяти (с. 52)), поэтому после стихотворения, в котором читатель узнает о первой встрече лирического героя с возлюбленной, не зная ее имени, появляется стихотворение «Судьбы смешная загогулина», в котором соединяются реальное и художественное пространства: «Моя ть Белла Ахмадулина», «Моя ты роковая Лиличка», «Моя моэмовская Джулия», «ть - чья-нибудь Татьяна Ларина» (с. 51). Прибегая к синтаксическому параллелизму при сравнении возлюбленной лирического героя, Борисов не называет ее по имени, отмечая черты ее характера или, возможно, театральные роли, потому что место их знакомства - театральные подмостки. 
В следующем стихотворении Борисов неожиданно меняет и интонацию, и форму повествования: перед нами не лирическая зарисовка, а трагическая история никому не известного человека, который «одевался в «Юникло» и покончил жизнь самоубийством, прожив «примерно сорок лет» (с. 50). С одной стороны, в этом стихотворении развивается один из главных мотивов сборника - мотив одиночества и бессмысленно прожитой жизни, что делает указанное стихотворение органичной частью сборника. С другой стороны, это финал трагедии, которая развернулась не в театре, а в жизни. Удивительно, что иллюстрации, помещенные в сборнике, также скрывают от читателя лицо возлюбленной, хотя силуэт молодого человека так или иначе напоминает самого автора.

Другие стихотворения рассказывают о бытовых заботах лирического героя: о быстро пролетевшем годе, о любви - истинной и искренней и законах, которым она подчиняется, о распорядке дня, о том, что кто-то «задолжал чирик» (с. 43). В них появляется форма замкнутого (темного, мрачного) пространства, представленного в образе метрополитена, который является частью «туманной Москвы» (с. 43). Таким образом, в сборнике пространственные образы вступают в антонимические отношения не только как ближние и дальние, горизонтальные и вертикальные, противопоставление наблюдается и внутри более крупного топоса.

Основное время повествования - прошедшее и - значительно реже - настоящее. Единственное стихотворение, в котором преобладают формы грамматического будущего времени - «Будет 2», предстающее криком лирического героя, признающегося в вечной любви и поэтому верящего в счастье. При этом Борисов вновь обращается к хрестоматийному блоковскому тексту, вписывая известные строки в свое стихотворение: «И будут ночь, аптека и фонарь, / и будет пропускать мячи вратарь» (с. 37).

\section{Заключение}

Метаморфозы времени и пространства представлены в сборнике на нескольких уровнях. Рамочные компоненты стихотворений определяют единство сборника, указывая на событие или главный посыл поэта, при этом чаще всего название стихотворения повторяется в одной из строчек (причем практически всегда - не в первой), а немногочисленные эпиграфы моделируют совершенно иное пространство, зачастую не связанное с текстом стихотворения на лексическом уроне. Помещенные в сборнике иллюстрации разделяют стихотворения не на циклы, а определенные периоды в жизни лирического героя, который «сокращал расставание» и стремился «отдаляясь, становиться ближе».

\section{Литература}

Борисов В. (2018). «Сокращая расставание». М.: РИПОЛ классик. 87 с.

Бурдина С.В. (2018). Гумилевские подтексты в поэмах А. Ахматовой // Вестн. Пермского ун-та. Российская и зарубежная филология. Т. 10, № 1. C. $79-89$. 
Верина У.Ю. (2016). Книга стихов в русской поэзии ХХ века: многообразие жанрово-композиционных форм // Вестн. Российского ун-та дружбы народов. Литературоведение. Журналистика. № 3. С. 15 - 23.

Голубков М.M. (2018). М.Горький и А.И.Солженицын: в литературном пространстве юбилейного года // Вестн. Московского ун-та. Серия 9: Филология. № 6. С. 141-153.

Ерохина И. (2016). Гений и злодейство: Пушкинский подтекст в ахматовском «Реквиеме» // Вопросы литературы. № 4. С. $198-200$.

Каминская Ю.В. (2019). «Пушкинский» и «ахматовский» тексты в романе В.В. Набокова «Пнин»// Вестн. Томского гос. ун-та. № 438. С. 45-53. DOI: $10.17223 / 15617793 / 438 / 6$

Кихней Л.Г. (2010). Семантика заглавий и смысловая целость поэтических книг Анны Ахматовой // Вестн. Российского ун-та дружбы народов. Теория языка. Семиотика. Семантика. № 2. С. 41 - 51

Клинг О.А., Орлова Е.И. (2019). Поэзия как словарь // Вопросы литературы. № 4. С. 107-119.

Лекманов О. (2010). Книга стихов Анны Ахматовой «Вечер» (1912) как «большая форма» (Электронный ресурс). URL: // http://lib.pushkinskijdom.ru/ Portals/3/PDF/Sborniki/Lesnaja\%20shkola/Lekmanov/Lekmanov2010.pdf (дата обращения 15.03.2020).

Маслова А.Г. (2020). Световая символика в поэзии Е.И. Кострова // Вестн. Томского гос. ун-та. № 450. С. 14-21. DOI: 10.17223/15617793/450/2

Тахо-Годи E.A. (2019). А.Ф.Лосев о гётевском учении о цвете, трагедии «Фауст» и романе «Страдания молодого Вертера»// Вопросы философии. № 9. С. 161-171.

Филатов А.В. (2016). Аксиологический подход к изучению книги стихов: онтологические ценности в «Чужом небе» Н.С. Гумилева // Новый филол. вестн. № 1 (36). С. 119 - 129.

Холиков А.А. (2019). Селение Винчи Д.С. Мережковского: трансформации текста от эгодокумента к художественной прозе // Новый филол. вестн. № 1 (48). C. $120-140$.

Хомяков C.A. (2018). Архитектоника рамочного текста (на примере «Поэмы без героя» А.А.Ахматовой) // «Litera». № 3. С. 57 - 68.

Чабан А.А. (2018). Николай Гумилев - рецензент Федора Сологуба // Русская литература. №1. С. 127-137.

\section{References}

Borisov V. (2018). «Shortening the Parting». M.: RIPOL klassik. 87 p. (In Russian).

Burdina S.V. (2018). Gumilev subtexts in poems by A. Akhmatova. Bulletin of Perm University. Russian and foreign philology, vol. 10, no. 1, pp. 79-89. (In Russian).

Chaban A.A. (2018). Nikolay Gumilyov - reviewer of Fyodor Sologub. Russian Literature, no. 1, pp. 127-137. (In Russian).

Erokhina I. (2016). Genius and villainy: Pushkin subtext in Akhmatov's «Requiem». Problems of Literature, no. 4, pp. 198-200. (In Russian).

Filatov A.V. (2016). Axiological Approach to Studying a Book of Poems: Ontological Values in «Alien Sky» by N.S. Gumilyov. New Philological Bulletin, no. 1 (36), pp. 119-129. (In Russian). 
Golubkov M.M. (2018). M. Gorky and A. I. Solzhenitsyn: in the literary space of the anniversary year. Bulletin of Moscow University. Series 9: Philology, no. 6, pp. 141-153. (In Russian).

Kaminskaya Yu.V. (2019). «Pushkin» and «Akhmatov» texts in the novel by V.V. Nabokov «Pnin». Bulletin of the Tomsk State University, no. 438, pp. 45-53. DOI: 10.17223 / 15617793/438/6 (In Russian).

Kihney L.G. (2010). Semantics of titles and semantic integrity of poetic books by Anna Akhmatova. Bulletin of the Peoples' Friendship University of Russia. Series: language theory. Semiotics. Semantics, no. 2, pp. 41-51. (In Russian).

Kling O.A., Orlova E.I. (2019). Poetry as a dictionary. Problems of Literature, no. 4, pp. 107-119. (In Russian).

Kholikov A.A. (2019). Vinci Settlement of D.S. Merezhkovsky: transformations of text from ego-document to fiction. New Philological Bulletin, no. 1 (48), pp. 120140. (In Russian).

Khomyakov S.A. (2018). Architectonics of the frame text (on the example of «Poem without a hero» by A.A. Akhmatova). Litera, no. 3, pp. 57-68. (In Russian).

Lekmanov O. (2010). The book of poems by Anna Akhmatova «Evening» (1912) as a «large form». Available at: http://lib.pushkinskijdom.ru/Portals/3/PDF/ Sborniki/Lesnaja\%20shkola/Lekmanov/Lekmanov2010.pdf (accessed 15.03.2020). (In Russian).

Maslova A.G. (2020). Light symbolism in the poetry of E.I. Kostrova. Bulletin of the Tomsk State University, no. 450, pp. 14-21. DOI: 10.17223 / 15617793/450/2(In Russian).

Taho-Godi E.A. (2019). A.F. Losev on Goethe's doctrine of color, the tragedy of «Faust» and the novel «The sufferings of young Werther». Problems of Philosophy, no. 9, pp. 161-171. (In Russian).

Verina U.Yu. (2016). The book of poems in Russian poetry of the twentieth century: a variety of genre-compositional forms. Bulletin of the Peoples' Friendship University of Russia. Series: Literary criticism. Journalism, no. 3, pp. 15-23. (In Russian).

\section{Sergey A. Khomyakov (Moscow, Russian Federation) \\ «Shortening The Parting» By Veniamin Borisov: Metamorphoses of Time And Space}

The article examines the specificity of the artistic time and space of $\mathrm{V}$. Borisov's poetry «Shortening the parting» (2018). The purpose of the study is to identify the features of the spatio-temporal organization and semantics of the frame elements. During the research, textological and hermeneutic methods were implied. The book's architectonics is based on the opposition of spatial and temporal forms. Such a construction is directly related to the semantics of poetry and the formation of a certain picture of the world of Borisov, whose lyrical character overcomes loneliness. The name of each poem is not only a reference to a specific source, but also a «key» important for understanding the underlying meaning (an indication of a fact or event). Seven color illustrations introduced into the collection make it possible to combine two types of art, and the poet to make his poems «visible» and create a chronicle of the main events. Contrasting in the collection near and far (city and village), closed and open (room and street) spaces, both in texts and in illustrations, $\mathrm{V}$. Borisov focuses on the feelings the protagonist 
experiences when he is forced to gradually overcome loneliness. The season depicted in the figures is summer, the semantics and images of which appear throughout the collection and which is often contrasted with winter paintings. The main topos, where events unfold, appears to be Moscow as a city that "absorbed" the features of Dostoevsky's Petersburg. The space of the capital appears as an alien to the lyrical character, who is forced to «wade through traffic, advertising, movie trailers.» Physical or cyclical time is either stated specifically («today»), or is present in allegorical images with accompanying motives. The effect of «slowed down» time can be achieved not only by the lack of indication of dates, but also by attachment to generally accepted or national events. Various spatial and temporal forms are presented in the book of poems «Shortening the Parting» by V. Borisov, which testifies to the complex organization of the collection and the author's intention.

Key words: time, space, «Shortening the Parting», Veniamin Borisov, chronotope, frame elements.

Sergey A. Khomyakov - Ph.D. in Philology; senior lecturer of Moscow medical and dental university of A.I. Evdokimov. Phone: +7-926-394-94-01; e-mail: khomjakov.sergey@mail.ru 